\title{
A PERDA DA GUARDA DE FILHOS: A VOZ DAS MULHERES, MÃES E USUÁRIAS DE DROGAS
}

\author{
PÉRDIDA DE LA GUARDA Y CUSTODIA DE HIJOS: LA VOZ DE LAS \\ MUJERES, MADRES Y USUARIAS DE DROGAS \\ LOSS OF CHILD CUSTODY: THE VOICES OF WOMEN, MOTHERS AND \\ DRUG USERS
}

\author{
Leila Marchezi Tavares Menandro을 Maria Lúcia Teixeira Garcia ${ }^{1}$ e \\ Rafaela Soares da Silva Uliana ${ }^{2}$ \\ ${ }^{1}$ Universidade Federal do Espírito Santo, Vitória/ES, Brasil \\ ${ }^{2}$ Instituto Federal do Espírito Santo, Vitória/ES, Brasil
}

RESUMO: A presente pesquisa analisa como mulheres que acessaram o CAPS ad III em situação de perda ou iminência de perda da guarda dos filhos se referem ao processo de cuidar de suas crianças e a perda da guarda das mesmas. A pesquisa é qualitativa e envolveu entrevistas com três mães. O cuidar para as entrevistadas é uma ação que envolve o atendimento a necessidades materiais e afetivas. Elas avaliaram seus cuidados de forma positiva. Entretanto, a prática de consumo de drogas as afasta do padrão idealizado de mulher e mãe, imputando a elas o papel de negligentes. A condicionalidade de retorno ou manutenção da guarda dos filhos à obrigação do tratamento apresenta-se como uma faca de dois gumes: para algumas mães essa obrigação faz com que elas aceitem e consigam fazer o tratamento; para outras, essa obrigação as leva a abandonar o tratamento e a possibilidade de reaverem os filhos.

PALAVRAS-CHAVE: Destituição do poder familiar; Maternidade; Drogas.

RESUMEN: La presente investigación analiza cómo las mujeres que acceden a los CAPS ad III en situación de pérdida o inminente pérdida de la guarda y custodia de sus hijos, se refieren al proceso de cuidar a sus niños y la perdida de la guarda custodia de estos. El estudio es cualitativo e involucró entrevistas con tres madres. El cuidar para las entrevistadas es una acción que involucra la atención a las necesidades materiales y afectivas. Ellas calificaran sus cuidados de forma positiva. Sin embargo, la práctica del consumo de drogas las aleja del modelo idealizado de mujer y madres, lo que le imputa el papel de negligentes. La condición se presenta como un arma de doble filo: para algunas madres, esa obligación hace que ellas acepten y consideren hacer el tratamiento; para otras, esta obligación las lleva a abandonar el tratamiento y la posibilidad de recuperar a sus hijos.

PALABRAS CLAVE: Destitución del poder familiar; Maternidad; Drogas.

ABSTRACT: This research analyses how women who accessed type III CAPS and who were in situation of loss, or imminent loss, of custody of their children, evaluate both the process of caring for their children and losing their custody. This qualitative research involved interviews with three mothers. Caring for the interviewees involved attending to both material and affective needs. They evaluated their care as being positive. However, their drug use practices distanced them from the idealized standard of womanhood and motherhood, imputing to them the role of being negligent. The obligation of treatment as a condition for the return of custody of the children to the mother is seen a double-edged sword: for some mothers this obligation led them to accept and get the treatment, while for others this obligation led them to abandon treatment and the possibility of getting their children back.

KEYWORDS: Deprivation of family power; Maternity; Drugs. 


\section{Introdução}

O uso abusivo de álcool e outras drogas é um fenômeno presente no mundo. A despeito da literatura reconhecer que há heterogeneidade social e cultural das(os) usuárias(os) de drogas (Sprícigo, Carraro, Fontoura, \& Schmidt, 2004), os estudos tendem a homogeneizar suas abordagens excluindo, por exemplo, as diferenças de gênero ${ }^{1}$ (Oliveira, Nascimento, \& Paiva, 2007). Quinby e Graham (1993, p. 131), afirmam que "o tratamento do abuso de substâncias em mulheres deve saber que existem significativas diferenças entre pacientes homens e mulheres". Se os estudos com enfoque de gênero ainda são poucos (Blume, 1990; Ravndal, 2011), são ainda mais escassos os que analisam as interações sociais entre mães usuárias de drogas e seus filhos (Silva, Pires, \& Gouvêia, 2015). Para Silva et al. (2015), estes estudos "não identificam se a mãe é a principal cuidadora, qual o papel do suporte social na sua vida ... quais as condições em que vivem as famílias dessas mães, quantos adultos cuidam da criança, qual a estrutura familiar, entre outros” (p. 94). Ao imputar à mãe a resposponsabilidade de cuidar, desconsiderando a existência de um suporte social, sua culpabilização e a perda da guarda de seus filhos tornam-se resultados possíveis.

A perda da guarda legal dos filhos entre mães usuárias de drogas tem mobilizado o debate sobre as implicações desta decisão sobre todos os envolvidos no processo. Dados sobre crianças e adolescentes, segundo os motivos que ensejam o acolhimento institucional, indicam que 11,3\% foram abrigados por terem pais que apresentavam consumo de drogas (Silva \& Aquino, 2005). De acordo com pesquisa do Conselho Nacional do Ministério Público (CNMP), mais de $80 \%$ dos encaminhamentos de crianças e adolescentes a instituições de acolhimento estão vinculados ao consumo de drogas dos pais, especialmente o crack.

No contexto europeu, há diferenças entre as políticas adotadas quanto à remoção de crianças de mães dependentes de drogas. Na Dinamarca e na Suécia, que operam esquemas de acolhimento, há uma mudança visando fornecer apoio para permitir que as mães usuárias de drogas permaneçam com seus filhos, ou pelo menos estabilizem a relação entre crianças e pais. Em países como Grécia, Espanha, Itália e Portugal, o foco recai sobre a família extensa para a garantia de cuidados às crianças (EMCDDA, 2000, p. 34). Ou seja, o tipo de ação do Estado guarda relação com o modelo de proteção social de cada país.

Este artigo explora um tema pouco usual na literatura: mães usuárias de drogas que acessaram o Centro de Atenção Psicossocial - álcool e outras drogas III (CAPS ad III) para tratamento por imposição da justiça para reaverem ou manterem a guarda dos filhos. A perda ou risco de perda da guarda dos filhos é uma questão para as mulheres usuárias de drogas e é também uma questão que vem desafiando os profissionais de diferentes áreas do conhecimento: famílias que vivem em "condições-limite de vida e sobrevivência ... frequentemente são questionadas pelos profissionais acerca da capacidade protetiva em relação a suas crianças ... sem trazer para o debate a fundamental presença do Estado como provedor de um sistema de garantia de direitos" (Berberian, 2015, p. 50).

Nesse sentido, o Estatuto da Criança e do Adolescente (Lei 8.609 de 1990) reafirma a família como instituição central "para a promoção e garantia dos direitos das crianças e dos adolescentes” (Moreira, 2014, p. 30), ao mesmo tempo em que o Estado é responsabilizado pela provisão de condições para o exercício desses direitos pelas famílias. De acordo com o que é preconizado pelo ECA, a convivência familiar é um direito das crianças e dos adolescentes. Quando a família falha no cumprimento dos seus deveres, o Conselho Tutelar 
(CT) pode ser acionado e tomar medidas que visem a garantia dos direitos das crianças e dos adolescentes, podendo resultar no acolhimento institucional desses sujeitos, bem como na perda do poder familiar dos pais (Crestani \& Rocha, 2018; Moreira, 2014).

Nossa reflexão emerge de uma situação concreta: em uma das atividades dentro do CAPS ad III, uma mãe relatou que seus filhos foram levados para instituição de acolhimento devido ao fato de ter sido denunciada ao CT por algum vizinho. Os profissionais do CT, segundo a usuária, levaram as crianças sob o pretexto de que estas não estariam sendo "bem cuidadas", imputando-lhe negligência no cuidado de seus filhos. Faleiros (2014), afirma que as taxas de incidência e prevalência da negligência são altas, mas as investigações sobre o tema são raras e o conhecimento limitado, indicando a necessidade de compreendermos um fenômeno multifacetado.

Ao perguntarmos para a usuária o que significava para ela a perda da guarda das suas crianças, ela respondeu "Não sei, eu cuidava muito bem dos meus filhos!". Esta resposta nos fez refletir sobre as exigências das instituições às famílias em seus cuidados com as crianças na atualidade. Essa questão tornou-se o ponto de partida para a nossa pesquisa.

\section{Maternidade, filhos e drogas}

Badinter (1985), desconstrói a visão tradicional do amor instintivo da mãe pelos filhos, situando histórica e socialmente a questão dos cuidados às crianças. Com o advento da sociedade burguesa e as transformações nas relações de produção e sociais, a medicina social começa a instituir demasiado valor aos cuidados com as crianças e, juntamente com o Estado, começa a difundir o ideal de cuidados de cada família ${ }^{2}$ com os próprios filhos (Reis, 2008). Tomando os cuidados dos filhos para si, a mulher passou a ter um lugar de destaque na sociedade. Na medida em que o papel principal da mulher se centrava na maternidade, esse status a aprisionava ao papel de mãe - o que lhe restringia outras possibilidades de atuação.

Nesse novo desenho que tomou a família moderna, os homens foram colocados no papel de chefes de família - donos dos filhos e da mulher; enquanto as mulheres ocupavam o papel de cuidar ${ }^{3}$ dos filhos e da casa (Badinter, 1985). As características socialmente prescritas, ensinadas e cobradas às mulheres foram marcadas por homogeneidade, na qual dois aspectos tinham especial proeminência: esposa prendada e dependente, e mãe afetuosa e dedicada (Coutinho \& Menandro, 2015, p. 55). Mas, é mister acrescentarmos outra dimensão: a de classe social. Enquanto as mães burguesas eram aliadas da medicina social, as mães pobres eram vistas como inadequadas e a sua condição de pobreza requeria ações de ajustamento, visto que sozinhas não conseguiriam acompanhar e reproduzir os costumes burgueses apontados como corretos. Portanto, as famílias pobres eram classificadas como incapazes ou incompetentes para tal coisa (Reis, 2008).

A preocupação com os cuidados aos filhos - alimentação, higiene, educação, etc. - tomava boa parte do tempo das mães que passavam a vida se dedicando à esses e ao lar (no caso das mães mais abastadas). Para as mães que necessitavam trabalhar, a vida impunha uma dupla jornada de trabalho, uma vez que se dedicar ao trabalho produtivo não lhe eximiu de cumprir seu papel feminino (Méndez, 2005). Ainda hoje o padrão dos cuidados maternos permanece como algo idealizado: Costa et al. (2014), afirmam que o cuidado 
materno representa "uma ação integral capaz de proporcionar a disseminação do carinho e do amor entre os componentes da família” (p. 153). Ou seja, essa lógica da considerada "a melhor" forma de cuidados ainda existe, bem como a imagem padrão da boa mãe.

As mulheres usuárias de drogas fogem ao duplo padrão esperado de mulher e de mãe. São alvo de estigma social e julgadas como promíscuas e incapazes de cuidar da família e dos filhos (Bolzan, 2015, Silva, 2005), além de serem vistas como irresponsáveis e egoístas (Cruz, 2012). Sendo assim, a questão das mães usuárias de drogas vem mobilizando o debate em torno da melhor forma para ofertar ajuda.

No Reino Unido, estima-se que há entre 250.000 e 350.000 crianças filhas de usuários problemáticos de drogas ... Muitas dessas mulheres [mães] estão relutantes em buscar cuidados por medo de julgamento negativo ou reação hostil da equipe de serviço ... [sendo necessários] serviços especializados, de suporte e anônimos para mães que usam drogas. (Maning, Best, Faulkner, \& Titherington, 2009, p. 377)

Nessa perspectiva, muitas mães perdem a guarda de seus filhos. No Brasil, entre os motivos para o acolhimento institucional de crianças, destaca-se a pobreza (35,5\%), que pode estar articulada a outros fatores, como o consumo de drogas ou envolvimento com o tráfico (Silva \& Aquino, 2005). O que temos é que, a partir da ideologia neoliberal e das suas implicações políticas e econômicas, as famílias são responsabilizadas pelos cuidados de seus membros. A destituição do poder familiar e/ou o acolhimento institucional, previstos no ECA, tem seguido a lógica de que "se as crianças/adolescentes são sujeitos de direitos e seus pais são responsáveis por garantir que eles sejam efetivados, é digno punir os pais quando esses direitos não estão sendo assegurados ou estão sendo violados" (Crestani \& Rocha, 2018, p. 5).

Sendo assim, este artigo analisa como as mães, que acessaram o CAPS ad III em situação de perda ou iminência de perda da guarda de seus filhos, referem sobre o processo de cuidar de suas crianças e a perda da guarda de seus filhos.

\section{Metodologia}

O locus da nossa pesquisa foi o CAPS ad III de Vitória (ES). Para chegarmos até as participantes da pesquisa - mulheres que já haviam perdido a guarda dos filhos e/ou estavam sendo advertidas pelo CT, incluindo gestantes - levantamos o número de usuárias que acessaram o CAPS ad III com essas características, a partir do levantamento dos prontuários de 2013 e 2014. Identificamos, então, que 480 mulheres foram atendidas no CAPS ad III no período selecionado. Desse total de 480, 130 não atendiam aos critérios do estudo (não estavam em idade fértil). Procedemos à leitura dos prontuários de 350 mulheres e, a partir dessa leitura, chegamos ao número de 41 usuárias sujeitos da pesquisa lheres que haviam perdido ou estavam ameaçadas de perder a guarda dos filhos. Dentre as 41 mulheres, sujeitos da pesquisa, entrevistamos 3 (Quadro 1), que atenderam aos seguintes critérios: ter perdido a guarda do(s) filho(s), ou estar na iminência de perdê-la; estar em tratamento como forma de condicionante para resgatar a guarda ou permanecer com o(s) filho(s); frequentar o CAPS ad III no período da coleta dos dados (entre janeiro e março de 2015); e consentir ser entrevistada. As entrevistas foram todas gravadas e transcritas, após assinatura do Termo de Consentimento Livre e Esclarecido (TCLE). 
Quadro 1: Dados de identificação das entrevistadas

\begin{tabular}{|c|c|c|c|c|c|c|c|}
\hline & Idade & Instrução & Trabalho & Moradia & $\begin{array}{c}\text { Início } \\
\text { do } \\
\text { consumo } \\
\text { de } \\
\text { drogas }\end{array}$ & $\begin{array}{c}\text { Forma de } \\
\text { acesso ao } \\
\text { CAPS ad III }\end{array}$ & $\begin{array}{l}\text { Beneficiária } \\
\text { de Programas } \\
\text { da Assistência } \\
\text { Social }\end{array}$ \\
\hline A 1 & 33 & $\begin{array}{l}\text { Ensino } \\
\text { Fundam. } \\
\text { I Incomp. }\end{array}$ & Desemp. & $\begin{array}{c}\text { Residia com } \\
\text { a filha em } \\
\text { casa paga com } \\
\text { Aluguel Social } \\
\text { da PMV }\end{array}$ & 12 anos & $\begin{array}{c}\text { Encaminhada } \\
\text { pelo } \\
\text { CREAS/SUAS }\end{array}$ & Sim \\
\hline $\mathrm{A} 2$ & 34 & $\begin{array}{l}1^{\circ} \text { Grau } \\
\text { Incomp. } \\
\left(8^{\circ} \text { ano }\right)\end{array}$ & $\begin{array}{l}\text { Autônoma (ven- } \\
\text { dia picolé, fazia } \\
\text { faxina) }\end{array}$ & $\begin{array}{c}\text { Residia com o } \\
\text { companheiro e } \\
1 \text { filho }\end{array}$ & 15 anos & $\begin{array}{l}\text { Vara da Infância } \\
\text { e da Juventude }\end{array}$ & Sim \\
\hline A3 & 24 & $\begin{array}{l}1^{\circ} \text { Grau } \\
\text { Incomp. } \\
\left(8^{\circ} \text { ano }\right)\end{array}$ & $\begin{array}{c}\text { Autônoma } \\
\text { (vendia picolés, } \\
\text { separava } \\
\text { reciclados, } \\
\text { ajudante de } \\
\text { cozinha) }\end{array}$ & $\begin{array}{c}\text { Chegou a } \\
\text { morar em casa } \\
\text { alugada } 29 \\
\text { dias (Aluguel } \\
\text { Social), mas } \\
\text { estava em } \\
\text { situação } \\
\text { de rua }\end{array}$ & 12 anos & Conselho Tutelar & Sim \\
\hline
\end{tabular}

As entrevistas "se referem a experiências ou processos específicos vividos ou testemunhados pelos entrevistados" (Delgado, 2006, p. 22). Buscávamos evidenciar um processo que traz em si uma dimensão social - vivido por mulheres na condição das nossas entrevistadas: jovens, pobres, usuárias de drogas e demandantes de programas sociais - e que não vêm ganhando destaque na academia. Para as entrevistas, utilizamos roteiro ${ }^{5}$ semi-estruturado, abordando os cuidados aos filhos, família e apoio nos cuidados às crianças.

Quanto à análise dos dados, utilizamos a análise de discurso, intentando revelar as nuances do discurso social que ali reverbera. Confrontamos, então, o discurso contido na fala das nossas entrevistadas com o nosso referencial teórico, de matriz crítica. Em relação aos procedimentos éticos, a pesquisa observou a Resolução ${ }^{\circ}$ 466/2012 do Conselho Nacional de Saúde - diretrizes e normas regulamentadoras de pesquisa envolvendo seres humanos, a saber: (a) participação livre e consentida (com assinatura de TCLE) e (b) garantia de anonimato. As participantes da pesquisa são identificadas pelas letras A, seguida do número ordinal. 


\section{Resultados e Discussão}

Para as entrevistadas, falar de cuidados implicava falar dos filhos. Nesse momento, o cuidar de si era parte do processo requerido a elas para cuidar dos filhos. As três mães entrevistadas traziam um dado recorrente - a relação com os filhos regulada e controlada pela justiça. A chegada ao CAPS ad III ocorreu após a perda da guarda de um ou mais filhos, por imposição de outrem. Ao falarem sobre cuidados com os filhos, isso requeria dessas mulheres pausa - o que falar? -, que suscita emoção - meu filho, minha filha -, e que gera reações diversas - raiva, choro, indignação. Falar envolvia, enfim, encantamento, dor e afeto:

"Ah, é minha vida. Meus filho é minha vida." (A2)

“O pensamento que dói. Fico muito sentindo a falta de meus filho." (A3)

"Sei lá... amor, carinho... assim, cuidar... dar muito amor, muito carinho e esquecer a vida errada." (A1)

A guarda dos filhos foi transferida à família extensa em dez casos (10 crianças). A adoção ocorreu em três casos (1 filho de A1 e 2 filhos de A3). A3 era a única que tinha um filho em situação de acolhimento institucional no momento da entrevista (Quadro 2).

Quadro 2: Dados sobre a guarda dos filhos

\begin{tabular}{|c|c|c|c|c|c|c|}
\hline \multirow{2}{*}{ Entrevistada } & \multirow{2}{*}{$\begin{array}{c}\text { No de } \\
\text { filhos }\end{array}$} & Guarda dos filhos & \multicolumn{3}{|c|}{ Situação da guarda dos filhos à época } \\
\cline { 4 - 7 } & & $\begin{array}{c}\text { Guarda } \\
\text { da mãe }\end{array}$ & $\begin{array}{c}\text { Fam. } \\
\text { Ext. }\end{array}$ & Adot. & $\begin{array}{c}\text { Acolh. em } \\
\text { Inst. }\end{array}$ \\
\hline A1 & 6 filhos & $\begin{array}{c}\text { perda da guarda de } \\
\text { O5 dos 06 filhos. }\end{array}$ & 1 & 4 & 1 & - \\
\hline A2 & 5 filhos & $\begin{array}{c}\text { chegou a perder } \\
\text { a guarda dos 05 } \\
\text { filhos. }\end{array}$ & 1 & 4 & - & - \\
\hline A3 & 5 filhos & $\begin{array}{c}\text { perda da guarda dos } \\
\text { 05 filhos. }\end{array}$ & - & 2 & 2 & 1 \\
\hline
\end{tabular}

Das três mães entrevistadas, apenas A2 tem contato com todos os filhos, uma vez que nenhum deles foi para a adoção, ficando com ela ou sob a guarda da família extensa:

"São boas. A minha relação com eles são boas." (A2)

A entrega da guarda das crianças para a família extensa, por mais que gere uma retirada do convívio com os filhos, não rompe por completo com os vínculos, visto que a mãe mantém um contato - mesmo que distante - com essa família e não necessariamente perde a sua condição de mãe. Para A2, os filhos representavam parte de si mesma, de sua história. A3, por sua vez, demonstrou um sentimento de tristeza, determinado pela ausência dos 
filhos. Para A1, além da questão do afeto, pensar nos filhos trazia a dimensão da vontade de mudar de vida e cuidar de si própria. Essas mulheres relembram que suas trajetórias de vida trazem percursos que se distanciam da imagem idealizada de família burguesa.

Como mulheres, pobres e usuárias de drogas, rememorar era lembrar que há filhos paridos, há filhos criados, há filhos perdidos e há filhos tirados. Há nesse trajeto uma relação com os filhos mediada por interferências internas e externas. Sobre a relação com os filhos, A 1 foi incisiva, dizendo que havia relação apenas com um deles - o que ela cria e cuida -, denunciando que não formou vínculos com os demais por vontade alheia. $\mathrm{O}$ mesmo notamos na fala de A3, uma vez que as suas crianças foram entregues para a família extensa ou foram adotadas, devido, aparentemente, ao seu envolvimento com as drogas.

"O meu filho tá em [município]... Meu outro filho, o Conselho Tutelar pegou ... e eu nunca mais vi meu filho... e minha outra filha foi doada... e meu outro filho tá lá em [cidade].” (A3)

A entrevistada A3 teve duas de suas crianças entregues para adoção por determinação judicial e um ainda permanecia acolhido em instituição. A intervenção do judiciário na vida familiar dessas mulheres gera um rompimento com os vínculos existentes, ou mesmo impede que o vínculo se estabeleça. Em geral, o que vimos é que as instituições, ao interferirem nas famílias, modificam os modos de vida desses sujeitos. Nos casos em que as crianças são institucionalizadas, os abrigos têm horários pré-definidos para as visitas das mães ou ainda, nos casos em que os bebês são retirados na maternidade, as mães não chegam a estabelecer vínculo com seus filhos recém-nascidos.

Ser mãe, traz consigo ainda a discussão sobre a presença-ausência dos serviços de saúde e o planejamento das gestações. Das três entrevistadas, apenas A3 afirmou ter planejado todas as crianças. A 1 e A2 responderam que algumas gestações foram planejadas, enquanto outras não.

"Planejei ter meu filho e eu nunca fui feliz ... Minha mãe nunca me aceitou grávida dentro de casa ... por isso meus filho foi jogado assim pro Conselho Tutelar.” (A3)

"Alguns eu planejei, alguns não. Planejei ter uma família, meus filho, mas no começo deu certo, depois deu tudo errado." (A1)

“Três eu planejei, mas os outros dois, não." (A2)

Estar grávida envolve uma relação esperada com os serviços de saúde (ambulatório de ginecologia e obstetrícia), e com a regulação sobre hábitos e comportamentos, entre eles a interdição ao consumo de drogas.

"Já usava droga desde os 12 anos... eu comecei a usar droga quando ganhei meu filho." (A3)

"Veio bem antes de todas as gestações. Desde os 12 anos que eu uso drogas." (A 1)

“Ó, nem todas gestação minha teve droga.” (A2) 
A melhoria da saúde das gestantes é um dos Objetivos do Milênio - propostos no ano 2000 pela Organização das Nações Unidas (ONU) - e o Brasil é um dos países signatários. Desde então, as equipes das unidades de saúde vêm acompanhando essa fase da vida das mulheres. Cruz (2012), afirma que apesar das usuárias de drogas apresentarem resistência em frequentar os serviços de saúde (devido, entre outras coisas, ao medo de perderem a guarda dos seus filhos), o período da gestação é propício para iniciar o tratamento, visto que a mulher fica mais suscetível à mudanças, aceitando os cuidados e o tratamento. Para tanto, as equipes das Unidades Básicas de saúde precisam estar preparadas para as demandas dessas mulheres, não reproduzindo "julgamentos negativos ou reações hostis" (Maning et al., 2009).

Sobre o dia-a-dia com os filhos, os cuidados com as crianças foram destacados por palavras relacionadas a afeto, lazer, higiene e alimentação. Como uma relação, o cuidar dos filhos pressupõe o eu (mãe) e o outro (filho).

Ah, tudo de bom. Eu perco meu tempo. Perco meu tempo brincando ... olhando. E cuidando, pra fazer feliz ... muito carinho, muito amor. Muita paixão ... Num deixar ninguém fazer covardia com a minha filha ... Dá atenção a ela, não bater nela, conversar com ela em vez de bater. (A1)

Dava mamadeira a ela certinho... e cuidava dela certinho... e minha filha nunca foi suja pra escola não ... O dia que a professora falou assim: tá meio suja a mochila... Eu peguei num dia e já lavava à noite ... ela era limpinha, ela nunca foi suja pra escola ... ia penteadim... Eu cuidei bem da minha filha. (A3)

Eu levava ele pro médico, eu brincava com ele, levava ele pra pracinha ... Eu usava droga do lado de fora de casa, deixava ele dentro de casa num chiqueirinho brincando e eu olhava para ele ... Nunca aconteceu dele cair nem nada. Nunca deixei acontecer nada com os meus filhos, sempre cuidei bem deles... (A2)

As três mulheres destacaram aspectos que designam o papel materno: cuidar e prover as necessidades da prole. A dimensão da higiene presente na fala das entrevistadas nos remete à padronização com valores burgueses. Ao pobre, estar e apresentar-se limpo é uma condição que lhe é requerida. Até os dias de hoje esse ideário higienista permanece na população, sendo o aspecto da limpeza uma preocupação no cuidado com os filhos e no seus lares.

É interessante a relação que essas mães fazem entre seu comportamento - consumo de droga - e a ideia de exemplo - os filhos não veem - pois ver a mãe consumindo droga é considerado por elas como inadequado e que deve ser evitado. Essas mães defendem seu papel de responsáveis por sua prole, afirmando que ninguém pode cuidar dos filhos como elas cuidam. Para elas, suas formas de cuidado, incluindo o amor materno, são insubstituíveis.

Meus filhos iam estar com outra família. Tá certo que, no caso, eles [Conselho Tutelar e juiz] acham que outra família é boa para eles, né? Melhor do que eu. Eu acho que não é. Porque eu sou a mãe. (A2)

... passou no [programa da televisão] ... A mulher que pegou a menina pra adotar? Adotou a menina $e$ [refere-se às maldades que a mãe adotiva fazia com a criança]. 
É a mãe que adotou a criança ... Fiquei horrorizada. Ai eu paro e penso: eles toma o filho da gente pra dá pra uma pessoa dessa aí maltratar... aí cada dia mais eu penso em minha filha... penso em melhorar mais. (A1)

O senhor, vossa excelência [juiz], podia me perdoar... me dá uma segunda chance... de mim dar... dar amor de mãe pela minha filha... me dá a segunda chance que eu amo minha filha. Não tira a minha filha de mim. Porque eu vou dar amor de mãe à minha filha ... ela é apegada a mim. (A3)

O que permeia todo esse discurso é a resposta que essas mães dão a uma questão que atravessa o nosso tempo: qual o limite da interferência do Estado na vida das famílias? O Estado brasileiro tem protegido nossas crianças? Quem deve cuidar delas? Para essas mães a resposta é nítida: elas - que como mães saberão ofertar o melhor cuidado. A1 e A3 tiveram filhos adotados por outras famílias e, no seu imaginário, os filhos podem estar sofrendo violências e maus tratos. A perda do vínculo com os filhos que foram tomados para adoção é motivo de sofrimento para as duas mães. Elas responsabilizam a justiça, as instituições e o Estado por esse rompimento dos laços com os filhos. Nesse sentido, retomamos a ideia de padronização das famílias, uma vez que a justiça, o Estado e as instituições que os representam reproduzem esses ideais, punindo aqueles que, por questões diversas, não se encaixam nos modelos idealizados. As famílias pobres sofrem interferência, e a perda da guarda das crianças é uma expressão desse fenômeno, sob a alegação de negligência ${ }^{6}$ (Ayres, 2002). A negligência imputada a essas mães - você não é boa mãe - mascara uma outra dimensão: a ausência do Estado na proteção a essas famílias.

As políticas públicas citadas por essas mulheres foram a política de assistência social (Centros de Referência de Assistência Social - CRAS, Centros de Referência Especializados de Assistência Social - CREAS, e da concessão do benefício assistencial Bolsa Família), a política de habitação (aluguel social do Projeto de Moradias Alternativas para pessoas em situação de rua no município de Vitória-ES), e a política de saúde (unidades básicas de saúde, CAPS ad III, entre outros). Ao acessar essas políticas, o encontro com os técnicos e a qualidade do atendimento, aparecem contraditoriamente como apoio e como controle.

Contava com [profissional da Secretaria de Habitação], o pessoal do CRAS e o pessoal do CREAS pra me dar força, sabe? ... minha mãe não me aceitava eu em casa, nunca me aceitou em casa de barriga ... eu morava na rua, já morei em abrigo e ia vivendo assim, sabe? Ai eu fui ganhar o aluguel social grávida. (A3)

Sou [atendida por CRAS e CREAS] ... Uma grande porcaria, porque uns ajudam, outros não ... essa menina que me tomaram, foi por causa da [profissional do CREAS]. Por isso que eu falo pra você ó... uma hora atrapalha, uma hora ajuda. Porque a [profissional do CREAS] foi delatar lá que eu morava na rua, aí eles foram e tomaram minha filha, nunca mais eu vi ela. (A 1)

O CRAS me deu muito suporte. Agora esse negócio de CREAS aí eu não gostei não ... Eu não gostei, você sabe por causa de quê? Eu nunca fui uma pessoa violenta. E eu acho assim ... que eles são para mães violentas. Mãe que viola os direitos das crianças. Eu não violei direito de criança nenhuma ... acho que eles não deveriam que ter se envolvido no meu problema. E para te falar a verdade, não gosto de ir lá. (A2) 
As instituições podiam atender ou não suas necessidades (nem sempre entendidas como direito social). Se o profissional conseguia atender as demandas, a instituição era avaliada como positiva, se algum profissional agisse de outra forma, a instituição era avaliada de forma negativa. A3 afirmava depender da profissional que a atendia. Esse tipo de avaliação - que julga as instituições de acordo com a pessoa que atende o usuário nos serviços - é um debate importante para os profissionais envolvidos nas áreas de Saúde e Assistência Social, em especial, para assistentes sociais e psicólogos. Visto que, apesar de ser preciso discutir e reconhecer os limites e possibilidades dos direitos no capitalismo, devemos sustentar a defesa e a reafirmação de direitos e das políticas sociais (Behring \& Boschetti, 2011).

Ainda sobre o acesso aos serviços públicos, somente A2 citou a unidade básica de saúde, referindo-se ao médico, o que mostra que essas mães recorrem a esse serviço apenas em situações emergenciais. Outro fato interessante é que a escola ou a creche, apesar de aparecer na fala de A2 e A3, não aparecem como instituições de suporte. Na fala de A1, por exemplo, a escola ${ }^{7}$ aparece como algo negativo. Isso pode ser explicado pelo fato da escola aparecer como uma aliada do CT. No caso de A3, que tem filho acolhido por instituição, percebemos idas e vindas nas opiniões sobre o CT, além da sua confusão com o que representa o Conselho e o que representa a justiça:

Ótima [se referindo a relação com o Conselho Tutelar], porque eu falei a verdade pro juiz ...A [profissional], ela é ótima ... A [outra profissional] é... gente boa. Ela só quer ver meu bem. Quer que eu se trate pra pegar minha filha. ... eu se dô com todo mundo do Conselho Tutelar ... Mas eu cacei a [profissional] várias vezes no Conselho Tutelar, só que ela não me atende... ninguém me atende... ninguém fala nada ... aí eu espero por Deus [refere-se ao desejo de rever um filho que foi adotado]. (A3)

Ao falar da atual situação com o Conselho Tutelar, A1 agiu de uma forma, mas quando remontamos o passado, sua fala mudou e a avaliação não poderia ser pior:

"Ah, tudo ótimo por enquanto.

[No passado] Ah, tudo de mau, tudo de ruim, ruim. Não gosto nem dessa palavra Conselho Tutelar ... Muito sentimento ruim”. (A1)

Com a opinião formada sobre o CT, A2 se manteve firme durante toda a sua fala:

Não, menina, minha relação com o Conselho Tutelar não foi boa não... porque... eles nunca foram lá para saber se...! ... Primeiro que as comissárias foram na minha casa. Falaram que iam voltar na outra quarta-feira e realmente voltaram, mas voltaram na escola do meu filho para pegar ele e levar embora ... (A2)

Os relatos das mães que perderam a guarda dos seus filhos revelam situações extremas de retirada das crianças ainda no interior das escolas e/ou creches pelo CT. Tanto A2 quanto A3 nos relataram essa violência. O CT é um órgão instituído para "promover uma política de direitos e sensibilizar o Estado e a sociedade a atenderem esses direitos" (Sequeira, Monti, \& Braconnot, 2010, p. 862), tendo como atribuição, entre tantas outras, a de "requisitar serviços públicos nas áreas de saúde, educação, serviço social, previdência, 
trabalho e segurança" (Lei 8.069, 1990, p. 84). Em sua função de controle, o CT apareceu retratado nos discursos das entrevistadas. Porém, a atribuição de requisitar outros serviços públicos não se fez presente. O CT é um órgão coletivo criado com intuito de proteção a crianças e adolescentes no Brasil e "representa uma intermediação entre o Estado e a sociedade" (Bulhões, 2010, pp. 110-111). Ainda segundo Bulhões (2010), o CT pode aplicar medidas cabíveis a ele, mas não deve ter caráter punitivo, cabendo ao Poder Judiciário apreciar e julgar os conflitos de interesse, fazendo cumprir determinações legais ou punir quem as infrinja.

Apesar do CT ter sido instituído visando representar a participação da sociedade na defesa dos direitos das crianças e adolescentes brasileiros - dispositivo importante em um contexto de violação de direitos -, a partir das nossas entrevistas, vemos que este órgão representa uma interferência na vida destas mães, fazendo parte do processo de retirada de seus filhos do convívio com as mesmas, com caráter punitivo, tratando a demanda como pontual e individualizada. Para Crestani e Rocha (2018), "à individualização da questão social se segue a possibilidade de culpabilização e criminalização da família. Mas essa criminalização não se dirige a todas as formas de ser-família, mas sim àquelas que estão historicamente associadas ao fracasso e incapacidade de cuidar dos filhos: as famílias pobres" (p. 6). Vale ressaltar, que os equipamentos de saúde também são compreendidos como instituições de controle, como é o caso das Unidades Básicas de saúde, dos hospitais e das maternidades (uma das entrevistadas teve seu bebê recém-nascido retirado, ainda na maternidade, pela Polícia Militar, que foi acionada pelos membros do CT).

Quanto ao suporte ou rede social - parentes, agregados, amigos ou vizinhos - como estratégia de sobrevivência e como ajuda para cuidar dos filhos, A2 e A3 relataram:

Nunca tive ... criei eles sozinhos. Às vezes eu chegava na creche até atrasada ... Eu vendia picolé na praia ... e deixava ele lá [na creche] em tempo integral né, que eu consegui. Quando eu chegava em casa ia dar cinco e meia, dez pras seis... Eu tinha que entregar o carrinho, correr pra lá, aí sempre chegava mais... mas não era só eu, tinha mais mães também. Então muitas vezes eu nem ligava por causa disso. (A2)

O suporte familiar e social, envolvendo pessoas que poderiam contribuir para o cuidado com as crianças, não se fez presente na vida dessas mulheres. Mesmo A3, que citou uma prima, tinha dificuldades em confiar nesse apoio, visto que a primeira vez que lhe perguntamos sobre rede de apoio, ela falou sobre as instituições e os profissionais. Apenas depois de uma pausa de tempo se lembrou da prima.

Essas mães possuem filhos sob a guarda da família extensa. Mesmo em alguns casos em que a mãe mantém algum contato com o filho que se encontra nessa situação, a relação com essa família acontece de forma delicada. Nos discursos das mães há a quebra de vínculo com a família - mães, pais e irmãos de ex-companheiros, tios distantes, agregados, entre outros. Dessa forma, compreendemos que o fato da família já ter sido solidária no passado não significa que contribuirá novamente. O que pudemos perceber é que há um limite bem posto entre 'já ter ajudado' e 'ajudar novamente’. Para Sarti (2005), o conceito de família para os pobres envolve uma rede de solidariedade. No caso dos sujeitos desta pesquisa está agregado à condição de pobreza o uso de substância psicoativa. Para algumas das mães há um rompimento com os vínculos familiares de origem em decorrência do uso de drogas. Família para as entrevistadas é composta por elas e por seus filhos, visto que não confiam 
em outras pessoas para ajudá-las. Ou seja, quando as crianças são retiradas, o que resta são elas mesmas, sozinhas. Diante de tudo o que vinham passando desde a perda ou ameaça da perda da guarda de seus filhos, essas mulheres experimentam sentimentos de solidão, culpa e esperança.

\begin{abstract}
"Sentimento de uma pessoa só, sozinha. Solitária". (A1)
Eu sinto que... eu não queria dizer isso não, mas eu fui irresponsável da minha parte sim ... Mas eu num perdi, né? que eu tô ganhando tudo de novo, né? Mas se fosse pra mim fazer tudo de novo eu não faria o que eu fiz ... Quer ver quando ele foi pro abrigo, que eu deixava ele lá chorando, meu coração cortava. Quero mais isso pra mim não. (A2)
\end{abstract}

Meu sentimento é... é eu ver meus filho, num sabe? Vê um dia que Deus pode realizar meu sonho de tentar ver meus outro filho, porque ... É saudade, muita saudade dos meus filho, não tem? O juiz não podia fazer isso com meu filho ... Eu creio em Deus que minha filha tá vindo pra casa, né? (A3)

A2 demonstrou arrependimento em relação às situações expostas a ela e aos filhos. Os elementos trazidos por ela foram de arrependimento, dor da perda, visitas à instituição de acolhimento e formação de vínculo afetivo entre mãe e filho, que muitas vezes não chega a acontecer por causa do distanciamento forçado. Há, também, na sua fala um desejo de mudança e do não retorno a uma época considerada por ela como triste. A3 mostrou desespero. No entanto, em todos os momentos em que o assunto sobre sua filha que estava em uma instituição de acolhimento surgia, ela mostrava otimismo. A esperança de retomada da guarda da filha veio acompanhada de um discurso religioso, remontando a fé, a mesma fé que a faz acreditar que irá rever os demais filhos, inclusive os que já foram adotados.

O que as três entrevistadas tinham em comum nas suas vidas era a condição de serem mulheres pobres. $\mathrm{O}$ consumo de drogas era mais um elemento na vida delas, mas que tomava outra proporção quando o assunto era a maternidade e o cuidado dos filhos. Essas mulheres lutam, a sua maneira, para manter ou resgatar a guarda dos seus filhos. Suas histórias de vida são marcadas por elementos que precisam ganhar visibilidade. São vidas que se cruzam por suas trajetórias e diversas marcas, que constituem várias histórias em construção.

\title{
Considerações finais
}

A partir das entrevistas com três mães em tratamento em um CAPS ad III como condicionante para reaverem ou permanecerem com a guarda dos filhos, constatamos que cuidar, para elas, vai além de prover necessidades materiais. Cuidar dos filhos é dar carinho, atenção, ou seja, a dimensão do afeto se sobrepõe aos aspectos materiais. Para essas mães, a higiene e o acompanhamento médico também são cuidados, no entanto, esses elementos não ocupam lugar central na sua forma de cuidar. Seus discursos expressaram as pressões sofridas pelas instituições de educação, saúde, assistência social, para um cuidar padronizado. Os cuidados são práticas aprendidas socialmente e as entrevistadas avaliavam suas formas de cuidado positivamente, compreendendo que esse cuidado é desempenhado melhor por elas do que por outras pessoas, visto que está apoiado no afeto materno. 
A exigência institucional de padronização dos cuidados, em geral, usa o modelo burguês como comparação. Se tomarmos como premissa o que se apresenta no aspecto visual das crianças, precisamos levar em consideração que a realidade socioeconômica gera dificuldades e limites ao acesso de bens e serviços. O preconceito que é impresso às famílias pobres, julgadas por sua aparência, formas de sobrevivência e resistência apareceram em seus relatos. A perda da guarda das crianças - impulsionada pela condição de pobreza das famílias e pelo uso de drogas pelas mães - agrava a situação dessas mulheres quanto ao próprio consumo de drogas. A retirada das crianças dessas mães resulta, de imediato, em uma falta de regularidade nas suas vidas e foi retratada por uma ação imposta por outrem - o CT. A condicionalidade de retorno ou manutenção da guarda dos filhos à obrigação do tratamento se apresenta como uma faca de dois gumes: para algumas mães a obrigação funciona, fazendo com que elas aceitem o tratamento e levem-no adiante, para outras, a obrigação as leva a piorar sua situação, abandonando o tratamento e a possibilidade de viverem com seus filhos.

Na maioria das vezes, essas mães não confiam ou não possuem uma rede social para ajudar em momentos que se faça necessário. Sarti (2005), afirma que as mulheres procuram apoio em outras mulheres para o cuidado com as crianças, mas as mães abordadas nesta pesquisa demonstraram não ter esse suporte. Dessa forma, não conseguem criar estratégias que envolvam uma rede social no auxílio dos cuidados das crianças para a manutenção e sobrevivência dessa família em casos extremos.

As instituições que formam a rede socioassistencial, que envolve tanto a saúde, quanto a assistência e a educação, são entendidas pelas mães como instituições de controle e não confiáveis, uma vez que há, pelos serviços, uma tendência ao julgamento sobre os cuidados das mães aos filhos como inadequados e fora dos padrões. Exime-se, assim, o Estado de sua responsabilidade em prover suporte para as famílias e as mulheres acabam por absorver todas as obrigações relacionadas aos cuidados. O acesso à rede não se dá de forma confortável e as entrevistadas personificam as instituições, avaliando-as conforme os atendimentos prestados, tomando uma dimensão de favor e ajuda. Há, assim, um esvaziamento da esfera dos direitos, fazendo com que essas mulheres temam em perder o que lhes pertence. 


\section{Notas}

1 Para Saffioti (2004) o conceito de gênero não é neutro. Ele "carrega uma dose apreciável de ideologia” (p. 136): a ideologia patriarcal. Esta ideologia cobre uma estrutura de poder.

2 Família é uma instituição social e guarda contradições em seu interior: se caracteriza por exercer proteção, afeto e cooperação e se caracteriza por disciplinar, oprimir e perpetuar a exploração das mulheres na tarefa da reprodução social (trabalho não pago). Trata-se, portanto, de uma instituição que cumpre funções sociais (Cisne, 2014).

3 Gama (2014) discute o 'trabalho doméstico', relacionado ao cuidado no contexto familiar ou domiciliar. Para a autora, o debate sobre o ‘trabalho do cuidado’ está associado à atividade feminina, em geral não remunerada, sem reconhecimento ou valorização social.

4. A análise do perfil destas mulheres foi abordada em outro artigo (https://periodicos.ufjf.br/index.php/libertas/article/view/18397).

$5 \quad$ O roteiro indicava apenas pontos disparadores para os relatos das mães no tocante à relação de suas histórias de vida e a maternidade. As perguntas versavam sobre os cuidados aos filhos, abordando estratégias utilizadas nos cuidados, acesso à rede de serviços, entre outros. O roteiro da entrevista se baseou no método da História Oral (Delgado, 2006).

${ }_{6}$ A produção social da ideia da família pobre, em especial a mãe pobre, como negligente em relação aos cuidados das crianças foi matéria de discussão por estudiosos no campo da psicologia brasileira, notadamente por Ayres (2002) e Ayres, Carvalho e Silva (2002).

7 Ao investigar as múltiplas relações entre trabalho, família e gênero, Gama (2014), afirma que as famílias enfrentam desafios quanto ao conflito entre trabalho e vida familiar. A autora apresenta a importância de instituições como a escola no enfrentamento desses conflitos a partir da possibilidade de ampliação do horário escolar, da oferta de alimentação gratuita, da cobertura de serviços de cuidado infantil, entre outros. 


\section{Referências}

Ayres, L. S. M. (2002). Naturalizando-se a perda do vínculo familiar. In M. L. Nascimento (Org.), PIVETES: a produção de infâncias desiguais (pp. 110-127). Niterói, RJ: Intertexto.

Ayres, L. S. M., Carvalho, M. S., \& Silva, M. M. (2002). Olhares sobre a instituição adoção: família e pobreza em questão. In M. L. Nascimento (Org.), PIVETES: a produção de infâncias desiguais (pp. 128-143). Niterói, RJ: Intertexto.

Badinter, E. (1985). Um amor conquistado: o mito do amor materno. Rio de Janeiro: Nova Fronteira.

Behring, E. \& Boschetti, I. (2011). Politica social: fundamentos e história. São Paulo: Cortez. Berberian, T. P. (2015). Serviço Social e avaliações de negligência: debates no campo da ética profissional. Serviço Social \& Sociedade, 121, 48-65.

Blume, S. B. (1990). Chemical Dependency in Women: Important Issues. The American Journal of Drug and Alcohol Abuse, 16(3-4), 297-307.

Bolzan, L. M. (2015). Onde estão as mulheres? A homogeneização da atenção à saúde da mulher que faz uso de drogas. Dissertação de Mestrado, Programa de Pós-graduação em Serviço Social, Pontifícia Universidade Católica do Rio Grande do Sul, Porto Alegre, RS.

Bullhões, R. R. R. (2010). Criação e trajetória do Conselho Tutelar no Brasil. Lex Humana, 1, 109-130.

Cisne, M. (2014). Feminismo e consciência de classe no Brasil. São Paulo: Cortez.

Costa, A. C. P. J., Silva, P. M., Rocha, P. C., Araújo, M. F. M., Araújo, T. M., \& Vieira, N. F. C. (2014). Alcoolismo materno e as implicações no cuidado da criança: estudo qualitativo. SMAD. Revista eletrônica saúde mental álcool e drogas, 10(3), 151-158.

Coutinho, S. M. S. \& Menandro, P. R. M. (2015). Representações sociais do ser mulher no contexto familiar: um estudo intergeracional. Psi. e Saber Social, 4(1), 52-71.

Crestani, V. \& Rocha, K. B. (2018). Risco, vulnerabilidade e o confinamento da infância pobre. Psicologia \& Sociedade, 30, e177502.

Cruz, V. D. (2012). Vivências de mulheres que consomem crack em Pelotas. Dissertação de Mestrado, Programa de Pós-graduação em Enfermagem, Universidade Federal de Pelotas, Pelotas, RS.

Delgado, L. A. N. (2006). História oral: memória, tempo, identidades. Belo Horizonte: Autêntica.

EMCDDA. (2000). Problems facing women drug users and their children. Recuperado de http://www.emcdda.europa.eu/system/files/publications/105/sel00 3en_69434.pdf.

Faleirros, J. M. (2014). Crianças em situação de negligência: a compreensão do fenômeno e o estabelecimento de parâmetros de avaliação. Tese de doutorado, Programa de Pós-graduação em Psicologia, Universidade de São Paulo, São Paulo.

Gama, A. S. (2014). Trabalho, família e gênero: impactos do direito do trabalho e da educação infantil. São Paulo: Cortez.

Lei n. 8.069, de 13 de jullho de 1990. (1990). Dispõe sobre o Estatuto da Criança e do Adolescente e dá outras providências. Acesso em http://www.planalto.gov.br/ccivil_03/leis/18069.htm Maning, V., Best, D. W., Faullkner, N. \& Titherington, E. (2009). New estimates of the number of children living with substance misusing parents: results from UK national household surveys. BMC Public Health, 9, 377-388.

Méndez, N. P. (2005). Do lar para as ruas: capitalismo, trabalho e feminismo. Fundação de Economia e Estatística, 5, 51-63.

Moreira, M. I. C. (2014). Os impasses entre o acolhimento institucional e o direito à convivência familiar. Psicologia \& Sociedade, 26(spe2), 28-37. 
Oliveira, J. F., Nascimento, E. R., \& Paiva, M. S. (2007). Especificidades de usuários de drogas visando uma assistência baseada na heterogeneidade. Escola Anna Nery Revista Enfermagem, 11(4), 694-698.

Quinby, P. M. \& Graham, A.V. (1993). Substance abuse among women. Prim Care, 20, 131140 .

Ravindal, E. (2011). Female poly drug abuse and psychopathology - gender differences: An overview. SERAF rapport, 3. Recuperado de https://pdfs.semanticscholar.org/4c93/efbae85822ff8410b5eba6c1f9a704dd9b6c.pdf

Reis, E. F. (2008). Produzindo mães e pais de famílias. In C. M. B. Coimbra, L. S. M. Ayres, \& M. L. Nascimento (Orgs.), PIVETES: encontros entre a psicologia e o judiciário (pp. 167-178). Curitiba: Juruá.

Saffioti, H. (2004). Gênero, patriarcado e violência. São Paulo: Fund. Perseu Abramo.

Sarti, C. A. (2005). A família como espelho: um estudo sobre a moral dos pobres. São Paulo: Cortez.

Sequeira, V. C., Monti, M., \& Braconnot, F. M. O. (2010). Conselhos tutelares e psicologia: políticas públicas e promoção de saúde. Psicologia em Estudo, 15(4), 861-866.

Sillva, D. S. (2005). Gênero e assistência às usuárias de álcool e outras drogas: tratamento ou violência? Dissertação de mestrado, Programa de Pós-graduação em Serviço Social, Pontifícia Universidade Católica do Rio de Janeiro, Rio de Janeiro.

Silva, E. R. A. \& Aquino, L. M. C. (2005). Os abrigos para crianças e adolescentes e o direito à convivência familiar e comunitária. Brasília, DF: Ipea Políticas Pociais - acompanhamento e análise, n.11. Recuperado de http://repositorio.ipea.gov.br/bitstream/ 11058/4571/1/bps n.11 ENSAIO3 abrigos.pdf

Silva, S. A., Pires, A. P., \& Gouveia, M. J. (2015). Toxicodependência e maternidade: uma revisão de literatura. Psicologia Clínica, 27(1), 83-100.

Sprícigo, J. S., Carraro, T. E., Fontoura, M. C. H., \& Schmidlt; K. R. (2004). Atenção ao usuário de drogas: um espaço para o enfermeiro. Texto \& Contexto Enf., 13(2), 296-302.

\section{LEILA MARCHEZI TAVARES MENANDRO}

https://orcid.org/0000-0002-9256-7535

Assistente Social, doutoranda no Programa de Pós-graduação em Política Social da Universidade Federal do Espírito Santo (PPGPS/UFES) e bolsista da CAPES. Integrante do Grupo de Pesquisa Fênix.

ENDEREÇO: Av. Fernando Ferrari, 514, Goiabeiras | Vitória - ES - CEP 29075-910.

E-MAIL: leilamtm@gmail.com

\section{MARIA LÚCIA TEIXEIRA GARCIA \\ https://orcid.org/0000-0003-2672-9310}

Doutora em Psicologia (USP). Professora do Departamento de Serviço Social, docente e coordenadora do Programa de Pós-graduação em Política Social da Universidade Federal do Espírito Santo. Bolsista de produtividade em pesquisa do $\mathrm{CNPq}$.

E-MAIL: lucia-garcia@uol.com.br 


\section{RAFAELA SOARES DA SILVA ULIANA}

\section{https://orcid.org/OOOO-0002-3594-5456}

Graduada em Ciências Sociais e Serviço Social pela Universidade Federal do Espírito Santo/UFES. Mestranda em Ensino de Humanidades pelo Programa de Pós-graduação em Ensino de Humanidades - Ifes campus Vitória. Integrante do grupo de pesquisa HISTOFIC - História e Filosofia da Ciência.

E-MAIL: rafassu@hotmail.com

\begin{tabular}{|c|c|}
\hline Histórico & $\begin{array}{l}\text { Submissão: 28/09/2018 } \\
\text { Revisão: 11/03/2019 } \\
\text { Aceite: } 12 / 04 / 2019\end{array}$ \\
\hline Contribuição dos autores & $\begin{array}{l}\text { Concepção: M.L.T.G; L.M.T.M; R.S.S.U. } \\
\text { Coleta de dados: L.M.T.M. } \\
\text { Análise de dados: L.M.T.M.; R.S.S.U.; M.L.T.G. } \\
\text { Elaboração do manuscrito: L.M.T.M.; M.L.T.G.; R.S.S.U. } \\
\text { Crítico revisões de conteúdo intelectual importante: } \\
\text { M.L.T.G. } \\
\text { Final aprovação do manuscrito: M.L.T.G; L.M.T.M. }\end{array}$ \\
\hline Financiamento & $\begin{array}{l}\text { Não houve financiamento para a pesquisa. } \\
\text { Maria Lúcia Teixeira Garcia é bolsista Pq do CNPq. }\end{array}$ \\
\hline $\begin{array}{l}\text { Consentimento de uso de } \\
\text { imagem }\end{array}$ & $\begin{array}{l}\text { Foi obtido o consentimento escrito dos participantes e/ } \\
\text { ou do detentor dos direitos autorais sobre a imagem. }\end{array}$ \\
\hline $\begin{array}{l}\text { Aprovação, ética e } \\
\text { consentimento }\end{array}$ & $\begin{array}{l}\text { Os procedimentos éticos se basearam na Resolução n. } \\
466 / 2012 \text { do CNS. O projeto foi aprovado no Comitê de } \\
\text { Ética da UFES (Plataforma Brasil) em } 26 \text { de dezembro } \\
\text { de } 2014 \text {, com o parecer n. } 926.930 \text {. }\end{array}$ \\
\hline
\end{tabular}

